\title{
¿Se puede embargar un bien fideicometido?: Según la SUNAT, ¡sí se puede! La protección del Fideicomiso en el Perú a propósito del pronunciamiento del Tribunal Fiscal
}

\author{
Martín Serkovic Pérez León* \\ Con colaboración de Antonella Puntriano*
}

\begin{abstract}
Resumen.- En el presente artículo, el autor brinda un panorama completo sobre los alcances de la figura del fideicomiso en el Perú y los beneficios que trae tanto para el sector privado como para el Estado. Una vez identificada la naturaleza del fideicomiso, centra su análisis en la interpretación que el Tribunal Fiscal le da a través de un reciente pronunciamiento.
\end{abstract}

Abstract.- In the present article, the author provides a complete overview of the scope of the trust fund figure in Peru and the benefits that brings both for the private sector and for the State. Once the nature of the trust is identified, he focuses the analysis in the interpretation that the Tax Court gives it through a recent pronouncement. 
Desde la década de los noventa, el Perú experimenta un crecimiento económico sostenido. Para ello, ha sido necesario que el mercado financiero y bursátil local se amolden a las circunstancias e implementen nuevas herramientas para mejorar las garantías de crédito.

Es así como a través del derogado Decreto Legislativo N770, Ley General de Instituciones Bancarias, Financieras y de Seguros, se introduce la figura del fideicomiso en el Perú. Posteriormente, el mencionado decreto fue derogado por la Ley N²6702, Ley General del Sistema Financiero y del Sistema de Seguros y Orgánica de la Superintendencia de Banca y Seguros (en adelante, "la Ley") que define al fideicomiso como aquella relación jurídica por la cual el fideicomitente (persona natural o jurídica) transfiere bienes de su propiedad en fideicomiso (patrimonio fideicometido) a un fiduciario (entidad que administrará el activo) con la finalidad de cumplir un fin en específico a favor del fideicomitente o un tercero denominado fideicomisario.
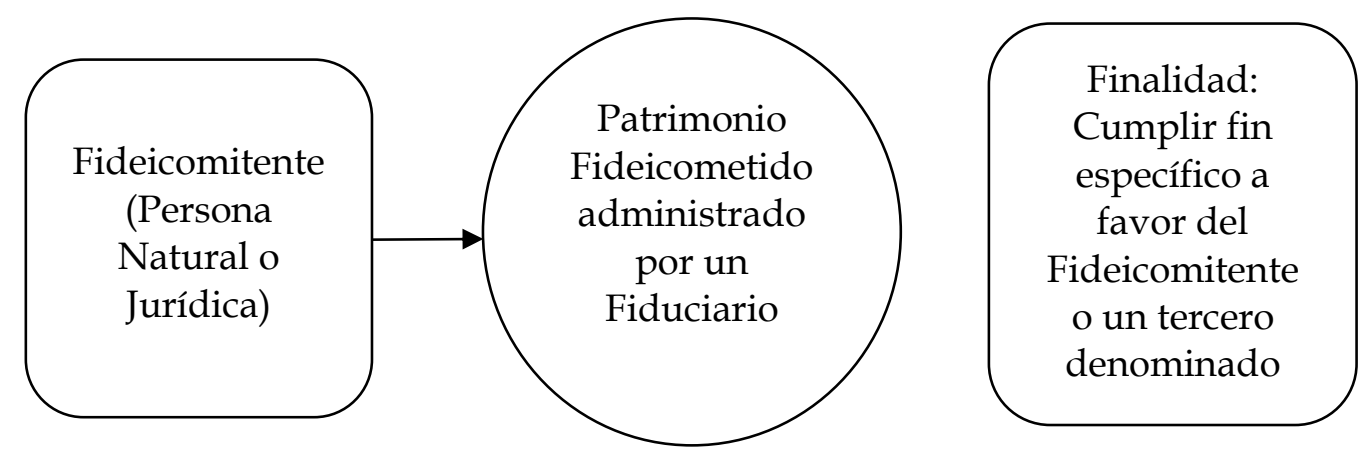

Consideramos pertinente mencionar que, al día de hoy, se puede constituir fideicomiso para todo y para todos. Por ejemplo, existen fideicomisos para garantizar créditos, para construir proyectos inmobiliarios, para gestionar deudas, para constituir un patrimonio familiar, entre otros. A modo de ejemplo, mencionaremos algunos ejemplos de tipos de fideicomisos en el Perú:

\begin{tabular}{|l|l|}
\hline \multirow{3}{*}{ Fideicomiso Bancarios } & $\begin{array}{l}\text { En este tipo de fideicomisos, el fiduciario } \\
\text { es una entidad bancaria. Este tipo de } \\
\text { fideicomisos se utilizan para garantizar el } \\
\text { cumplimiento de obligaciones } \\
\text { previamente adquiridas, mediante el cual } \\
\text { se constituye un patrimonio autónomo }\end{array}$ \\
\hline
\end{tabular}


¿Se puede embargar un bien fideicometido?: Según la

SUNAT, jsí se puede!

La protección del Fideicomiso en el Perú a propósito del pronunciamiento del Tribunal Fiscal

\begin{tabular}{|c|c|}
\hline & $\begin{array}{l}\text { (inembargable) creado para determinados } \\
\text { fines. Existen } 4 \text { tipos de fideicomisos } \\
\text { bancarios: de administración de flujos, de } \\
\text { garantía, inmobiliarios y de inversión. }\end{array}$ \\
\hline Fideicomiso de Titulización & $\begin{array}{l}\text { Esta clase de fideicomisos se regulan a } \\
\text { través de la Ley de Mercado de Valores. } \\
\mathrm{Su} \text { principal característica es que se } \\
\text { emiten valores mobiliarios que } \\
\text { representan derechos de crédito } \\
\text { respaldados por patrimonio que se } \\
\text { encuentra sometido al fideicomiso. } \\
\text { Ejemplo: emisiones de bonos en el } \\
\text { mercado de capitales. }\end{array}$ \\
\hline $\begin{array}{l}\text { Fideicomiso Puente } \\
\text { Inmobiliario }\end{array}$ & $\begin{array}{l}\text { Sirve para garantizar que un terreno será } \\
\text { utilizado para la realización de un } \\
\text { proyecto inmobiliario en específico, } \\
\text { mientras se realizan los estudios de } \\
\text { títulos y trámites administrativos } \\
\text { correspondientes. En este escenario el } \\
\text { patrimonio fideicometido está constituido } \\
\text { por el terreno que adquirió el } \\
\text { fideicomitente con ayuda de un } \\
\text { inversionista (fideicomisario), quien } \\
\text { participará en el desarrollo del proyecto } \\
\text { inmobiliario. }\end{array}$ \\
\hline $\begin{array}{c}\text { Fideicomiso Escrow o } \\
\text { Condicionado }\end{array}$ & $\begin{array}{l}\text { Su principal función es garantizar una } \\
\text { operación de compraventa de activos } \\
\text { (usualmente empresas, aunque también } \\
\text { pueden ser inmuebles) para que esta se } \\
\text { realice con mayor transparencia y } \\
\text { facilidad hasta que se logren concretar } \\
\text { todas las condiciones otorgadas por las } \\
\text { partes. }\end{array}$ \\
\hline
\end{tabular}




\begin{tabular}{|c|l|}
\hline Fideicomiso de Gestión de & $\begin{array}{l}\text { La principal característica de este tipo de } \\
\text { fideicomisos es que el cumplimiento de } \\
\text { las obligaciones generadas por el } \\
\text { financiamiento se aísla del fideicomitente } \\
\text { y recaen exclusivamente sobre el } \\
\text { patrimonio autónomo generado por el } \\
\text { fideicomiso de gestión. Para este tipo de } \\
\text { operaciones se constituyen dos } \\
\text { fideicomisos: uno de gestión y otro de } \\
\text { garantía. }\end{array}$ \\
\hline Fideicomiso de Control de & $\begin{array}{l}\text { Este fideicomiso se utiliza principalmente } \\
\text { para obras públicas y privadas licitadas } \\
\text { con la finalidad de administrar los fondos } \\
\text { otorgados por la entidad contratante al } \\
\text { ganador de la Buena Pro (fideicomitente) } \\
\text { para la realización de la obra. Cabe } \\
\text { señalar que para participar de la obra, el } \\
\text { fideicomitente tuvo que entregarle cartas } \\
\text { fianza a la entidad. }\end{array}$ \\
\hline
\end{tabular}

Ahora bien, nos preguntamos, ¿por qué la gente opta por un fideicomiso? Consideramos que la respuesta es sencilla: porque, además, de ser un vehículo jurídico que brinda practicidad para estructurar negocios y financiamiento tanto de personas naturales como jurídicas, el fideicomiso brinda absoluta seguridad jurídica a todas las partes intervinientes, toda vez que el patrimonio fideicometido se encuentra excluido del patrimonio del fideicomitente, del fiduciario y del fideicomisario. Asimismo, el fideicomiso no permite que el patrimonio fideicometido se destine a un fin distinto para el que fue constituido; tampoco permite modificar la estructura o contenido, así como una terminación anticipada.

Pero, ¿qué significa que el patrimonio fideicometido se encuentre excluido del patrimonio de las partes intervinientes en el fideicomiso? De acuerdo a la Ley, significa que el patrimonio fideicometido no responde por las obligaciones del fiduciario o del fideicomitente y tratándose de las obligaciones de los fideicomisarios, tal responsabilidad solo es exigible sobre los frutos o las prestaciones que se encuentran a disposición de ellos, de ser el caso. 
¿Se puede embargar un bien fideicometido?: Según la

SUNAT, jsí se puede!

La protección del Fideicomiso en el Perú a propósito del

pronunciamiento del Tribunal Fiscal

Cabe señalar que de acuerdo al artículo 254 de la Ley, los bienes que integran el patrimonio fideicometido solo se encuentran afectos al pago de las obligaciones y responsabilidades que la empresa fiduciaria contraiga en ejercicio del dominio fiduciario por los actos que efectúe para el cumplimiento de la finalidad para la que fue constituido el fideicomiso.

En ese sentido, el patrimonio fideicometido es un patrimonio autónomo que no goza de personería jurídica. SI bien el mercado bancario y bursátil peruano se encuentra familiarizado con la figura del fideicomiso, existe aún mucha discrepancia respecto de que si con el fideicomiso se transfiere o no propiedad.

Al respecto, a través del fideicomiso se plantea la separación patrimonial prescindiendo de la personalidad jurídica. Dicho ello, consideramos que a través del fideicomiso no se transfiere propiedad, entendiendo como tal la transferencia de todos los atributos de la propiedad de acuerdo con nuestra legislación. Simplemente se transfiere un derecho de carácter temporal, que permite al fiduciario administrar y gestionar el patrimonio fideicometido para el cumplimiento del fin o fines del fideicomiso. Es una trasferencia condicionada, con limitaciones específicas de actuación sobre el bien o derecho transferido.

En palabras de Freddy Escobar Rozas:

“(...) es absolutamente imposible sostener que el fiduciario adquiere el derecho de propiedad sobre el activo transferido por el fideicomitente. En efecto, el fiduciario jamás adquiere algunas de las facultades que conforman el contenido del referido derecho, como por ejemplo la facultad de destruir el bien o la de modificarlo. Por tanto, sea cual sea la 'titularidad' otorgada al fiduciario, aquélla no puede ser equiparada a la propiedad que tenía el fideicomitente sobre los activos"1.

Teniendo en cuenta que no se transfiere propiedad absoluta de manera definitiva, ya que la naturaleza de fideicomiso es temporal, debido a que tiene una fecha de caducidad que dependerá del fin para el cual ha sido creado, podemos afirmar que nos encontramos ante un vehículo jurídico idóneo para llevar a cabo distintos negocios, como por ejemplo, financiamientos a través de emisión de bonos, construcción de proyectos de infraestructura, desarrollo de

1 ESCOBAR ROZAS, Freddy. “Tradiciones, transplantes e ineficiencias: el caso del fideicomiso peruano”. En IUS ET VERITAS N³2, Pág.: 119. 
proyectos inmobiliarios, protección de legados culturales, garantizar reestructuraciones de créditos y obligaciones, asegurar flujos de repago en financiamientos, entre muchos otros.

Solo por nombrar algunos ejemplos locales, el centro comercial Mega Plaza Cono Norte, operado por "Inmuebles Panamericana S.A.", canceló el total de la deuda contraída con diversos bancos locales en el año 2002 para la construcción del centro comercial a través de dos emisiones de bonos titulizados. Este proceso de Titulización consistió en la transferencia en fideicomiso de un conjunto de activos futuros a través del patrimonio fideicometido.

Otro ejemplo de fideicomiso en el mercado local, es el caso de "Los Portales S.A.", empresa inmobiliaria que también se dedica al rubro hotelero y de los estacionamientos, durante los años 2013 y 2015 obtuvo financiamiento por la suma de US\$ 60 millones de dólares a través de una empresa subsidiaria del BBVA Continental denominada Continental Sociedad Titulizadora, a través de la emisión de bonos titulizados. Para ello se constituyó fideicomiso sobre varios proyectos inmobiliarios de Los Portales.

Un último ejemplo que nos gustaría citar es el caso de la Resolución Ministerial N²51-2016-MEM/DM a través del cual el Ministerio de Energía y Minas aprueba el reglamento que regula la constitución de fideicomiso en garantía sobre bienes inmuebles para garantizar los planes de cierre de minas. A través de dicho cuerpo normativo, el Estado pretende que el titular de la actividad minera constituya fideicomiso sobre bienes inmuebles distintos a las concesiones mineras a efectos de garantizar que se cubran los costos que implican las medidas de rehabilitación para los periodos de operación de cierre final y post cierre de mina a favor del fideicomisario, que en este supuesto está representado por el Ministerio de Energía y Minas.

Como podemos ver en los ejemplos citados en los párrafos precedentes, la figura del fideicomiso no es solo utilizada por el sector privado, también es utilizada por el estado, para entre otros fines, asegurar el cumplimiento de las obligaciones que mantienen los privados en proyectos de infraestructura, concesiones o contrataciones públicas.

Otra de las ventajas que ofrece el fideicomiso, según Javier Darío Bregante Tassara, es que permite constituir un patrimonio autónomo ${ }^{2}$ como una

2 Resulta necesario resaltar que un patrimonio fideicometido es un patrimonio autónomo, por lo que toda referencia a un patrimonio autónomo debe entenderse como un patrimonio fideicometido. 
¿Se puede embargar un bien fideicometido?: Según la

SUNAT, jsí se puede!

La protección del Fideicomiso en el Perú a propósito del

pronunciamiento del Tribunal Fiscal

alternativa eficiente para gestionar riesgos de forma integral debido al principio de separación patrimonial y el principio de gestión especializada 3 .

El principio de separación patrimonial supone que los activos y/o flujos que conforman un patrimonio fideicometido son distintos al patrimonio del fideicomitente, fiduciario y fideicomisario. Ello permite que dicho patrimonio se encuentre excluido de un posible embargo, secuestro o hasta un escenario de insolvencia o iliquidez de las empresas o personas naturales que conforman el fideicomiso.

Por otro lado, el principio de gestión especializada establece que el fiduciario solo puede administrar el patrimonio fideicometido dentro de los parámetros y límites establecidos por el fideicomitente, lo que garantiza el cumplimiento de la finalidad por la cual se constituyó el fideicomiso.

Los principios mencionados líneas arriba conllevan muchas ventajas: (i) reducen costos de transacción entre los agentes de mercado; (ii) permiten establecer reglas de juego claras para la administración y gestión del fideicomiso; (iii) brindan seguridad jurídica; y, (iv) permiten constituir un patrimonio autónomo ajeno a riesgos inherentes a los patrimonios de las partes intervinientes.

Javier Darío Bregante Tassara en su Tesis "El Derecho de los Patrimonios Autónomos: un estudio transversal del Fideicomiso, la Titulización, los Fondos Mutuos y los Fondos de Inversión" se cuestiona sobre quién es el titular del patrimonio autónomo. El sostiene que el patrimonio autónomo es el "titular" del patrimonio autónomo. ¿Cómo explica ello? Debido al reconocimiento legal que se le concede a la separación de un conjunto de bienes, derechos y obligaciones del patrimonio del fiduciario, del partícipe o fideicomitente, y del beneficiario o fideicomisario, así como de los destinatarios de los bienes remanentes.

Coincidimos con Javier Darío Bregante Tassara en cuanto a que los patrimonios autónomos tienen titularidad, de lo contrario cómo podría explicarse que tengan la facultad de adquirir derechos y obligaciones, contratar con terceros, participar como parte en un proceso judicial, etc. Lo que sí debe

3 BREGANTE TASSARA, Javier Dario, “El Derecho de los Patrimonios Autónomos: un estudio transversal del fideicomiso, la Titulización, los fondos mutuos y los fondos de inversión". Tesis para optar por el Título de Abogado -PUCP. Página: 37 
tenerse en claro, es que bajo ningún escenario el titular de dicho patrimonio podría ser el fideicomitente, el fiduciario o el fideicomisario, debido al principio de separación patrimonial mencionado líneas arriba.

Ahora bien, teniendo en consideración que el patrimonio autónomo puede contratar con terceros, demandar, etc., ¿qué sucede cuando un patrimonio fideicometido no cumple con sus obligaciones? ¿Quién debe responder por dicho incumplimiento? En la práctica, solo se debe responder con todos los bienes y derechos que conforman dicho patrimonio. Bajo ningún escenario el patrimonio fideicometido debe responder por las deudas del fideicomitente, fiduciario o fideicomisario, toda vez que la figura del fideicomiso se encuentra respaldado por el principio de separación patrimonial.

Resulta imprescindible resaltar que el artículo 253 de la Ley de Bancos establece que el patrimonio fideicometido no responde por las obligaciones del fideicomitente, del fiduciario y, tratándose del fideicomisario, solamente responde por la parte que se encuentre a su disposición y no establece excepción alguna a este criterio.

El mencionado artículo es bastante claro y fácil de comprender, entonces, ¿cómo el Tribunal Fiscal puede a través de las Resoluciones Nº0772-4-2015 y 02048-10-2015, ordenar un embargo trabado por la SUNAT sobre unos bienes que conforman un fideicomiso?

Antes de proceder con el análisis de las mencionadas Resoluciones del Tribunal Fiscal, consideremos pertinente resumir brevemente los antecedentes del caso para un mejor entendimiento:

- En el año 2006, la empresa Veritas Edificaciones S.A.C (en adelante, "Veritas") constituyó en calidad de fideicomitente un fideicomiso con el Banco de Comercio, este último en calidad de fiduciario.

- La finalidad del fideicomiso era desarrollar un proyecto inmobiliario sobre el inmueble denominado "El Potrero" ubicado en la ciudad de Chiclayo.

- $\quad$ Sobre la partida matriz del inmueble, se independizaron 1220 lotes de vivienda, dos de los cuales se vieron afectados con una medida cautelar de embargo

- $\quad$ En el año 2010, el Banco de Comercio renuncia a su rol de fiduciario y transfiere al Fondo Mi Vivienda el fideicomiso y como consecuencia el patrimonio fideicometido del contrato. 
¿Se puede embargar un bien fideicometido?: Según la

SUNAT, jsí se puede!

La protección del Fideicomiso en el Perú a propósito del

pronunciamiento del Tribunal Fiscal

- $\quad$ Mediante las Resoluciones Coactivas N0230071885144 y 0230071885186 de fecha 02 de agosto de 2013, la SUNAT dispuso trabar embargo en forma de inscripción sobre dos lotes pertenecientes al patrimonio fideicometido.

Es difícil entender como la SUNAT, siete años después de haberse constituido el fideicomiso, pretende trabar embargo sobre dos lotes pertenecientes a un patrimonio fideicometido, más aun teniendo en cuenta que a través del Informe $\mathrm{N}^{\circ}$ 254-2005-SUNAT/2B0000 del año 2005, se establece que no procede trabar medidas cautelares sobre los bienes y/o derechos transferidos por el deudor tributario en calidad de fideicomitente, salvo que dichas medidas hayan surtido efecto con anterioridad a la transferencia fideicomisaria de tales bienes y/o derechos.

Ante el embargo trabado por SUNAT sobre dos lotes fideicometidos, Fondo Mi Vivienda interpuso una intervención excluyente de propiedad, argumentando que los inmuebles afectados le habían sido transferidos en calidad de dominio fiduciario. SUNAT declaró inadmisible dicha intervención excluyente de propiedad y, posteriormente, el Tribunal Fiscal confirmó lo resuelto en primera instancia.

Cabe señalar que el Tribunal Fiscal no aceptó la intervención excluyente de propiedad presentada por el fiduciario (Fondo Mi Vivienda), basándose en un precedente de observancia obligatoria (Resolución $\left.N^{\circ} 08184-1-2007\right)$ que señala que la tercería o intervención excluyente de propiedad es la vía por la cual un tercero ajeno al procedimiento de cobranza coactiva invoca su derecho de propiedad respecto de un bien embargado por una deuda tributaria correspondiente a otro sujeto(deudor tributario), y tiene como finalidad que se tutele el derecho de propiedad y se impida la ejecución de la medida de embargo sobre el bien que le pertenece.

El Tribunal Fiscal señala que, como a través de un fideicomiso no se transfiere propiedad absoluta y plena, sino el dominio fiduciario, lo cual solo representa una cesión de dominio condicionada a una finalidad específica, no es jurídicamente posible que un fiduciario interponga una tercería o intervención excluyente de propiedad toda vez que no es el titular del bien en disputa y, por lo tanto, no puede invocar su defensa sobre un derecho de propiedad.

No es materia del presente artículo profundizar respecto a que si la medida 
planteada por el Fondo $\mathrm{Mi}$ Vivienda para resguardar el patrimonio fideicometido fue la correcta o no como estrategia de defensa; pero si queremos resaltar el escaso análisis desarrollado por el Tribunal Fiscal en este caso en específico. De una simple lectura a las Resoluciones del TF, se puede apreciar que solo se limita a pronunciarse respecto de la medida de intervención excluyente de propiedad presentada por la recurrente, pero no hace un correcto análisis sobre la inembargabilidad del patrimonio fideicometido.

Incluso el Tribunal Constitucional, mediante sentencia de fecha 13 de agosto de 2009 (Exp N00079-2008 -PA/TC) resuelve que el dominio fiduciario es un derecho real por cuanto tiene carácter de inmediato y absoluto, y que trae como consecuencia que el patrimonio fideicometido sea distinto al patrimonio de fideicomitente y que no responde por las obligaciones de dicha persona. Asimismo, sostiene que siendo el fideicomiso un patrimonio autónomo, tiene existencia independiente para efectos legales y contables distintas a la del fideicomitente.

A la fecha, el Fondo Mi Vivienda ha planteado una demanda contenciosa administrativa contra las referidas resoluciones del Tribunal Fiscal que afectan su derecho como fiduciario. Dicho ello, y por lo resuelto en el mencionado informe de la SUNAT, y en la sentencia del Tribunal Constitucional; se puede concluir que el proceso judicial planteado por el Fondo Mi Vivienda debería ser resuelto declarando que los patrimonios autónomos en fideicomiso son inembargables, y que el fiduciario es capaz de defenderlos de acuerdo a lo estipulado en el artículo 252 de la Ley de Bancos, el mismo que establece que el fiduciario goza de plenas facultades de reivindicación sobre los bienes que conforman el patrimonio fideicometido.

La ley de bancos establece en el artículo 245 que sólo se pueden afectar fideicomisos iniciando proceso de nulidad de fideicomiso por fraude de acreedor dentro del plazo de 6 meses desde que se publica el fideicomiso en el diario oficial El Peruano. La SUNAT y cualquier otro acreedor con legítimo derecho deben transitar ese camino y ningún otro que ponga en peligro la herramienta que ha permitido financiar, con mayor seguridad de los inversionistas, tantos proyectos.

El precedente que se crearía si es que no se declara en la instancia contenciosa administrativa la nulidad de la resolución del Tribunal Fiscal, sería nefasto, y las consecuencias para las operaciones de financiamiento $\mathrm{y}$, sobre todo, para financiamiento de proyectos de infraestructura, serían claramente negativas. La herramienta del Fideicomiso como ente que recibe bienes, y derechos 
¿Se puede embargar un bien fideicometido?: Según la

SUNAT, jsí se puede!

La protección del Fideicomiso en el Perú a propósito del

pronunciamiento del Tribunal Fiscal

presentes y futuros, conformando un patrimonio autónomo, que permite garantizar un financiamiento $\mathrm{o}$, crear la estructura de pago de dicho financiamiento, entre muchas otras posibilidades, se vería totalmente debilitada, haciendo que pierda su naturaleza de autonomía, y que por lo tanto quede expuesta a acciones de terceros, que afectarían directamente la estructura implementada. Perdería su naturaleza y su razón de ser.

El resultado sería claro, el financiamiento en los proyectos de infraestructura se encarecería, los requerimientos de garantías de terceros serían mayores, así como los de un capital inicial mayor, equipos en garantía, y demás exigencia que limitarían la flexibilidad en la gestión del proyecto y que desincentivarían la inversión en este tipo de proyectos. 